\title{
Teaching the Sound Concept: A Review of Science and Physics Education Postgraduate Theses in Turkey
}

\author{
By Müge Aygün* \& Yasemin Hacıoğlu ${ }^{+}$
}

\begin{abstract}
The purpose of this study is to review the postgraduate theses on science/physics education in Turkey to guide the teaching of the sound concept. Although the theses examined within the scope of this study belong to a certain region, the previous literature shows us that the learning difficulties/misconceptions are generally independent of culture. Thirty-three theses in the database of The Council of Higher Education Thesis Center were analyzed inductively in the semi-systematic review process. For this, the stages of content analyses were used: Elimination and coding, placing them in themes, ensuring reliability and validity were followed respectively. Unit of analyses was conclusions of the theses and suggestions of the theses. In conclusion, both conventional and contemporary approaches have a positive effect on achievement or conceptual change on the sound concept. On the other hand, students and teachers/ candidates, in general, cannot relate their knowledge of sound to daily life, their level of knowledge is inadequate, and they have misconceptions/errors and confusions. It is beneficial to consider this situation in education. The most important output of this study is the lists of possible misconceptions or confusion about the concept of sound. Teachers and researchers can use these lists in their lessons or research.
\end{abstract}

Keywords: education, physics, science, sound, thesis

\section{Introduction}

Longitudinal mechanical waves in the 20-20,000 Hertz frequency range formed as a result of the vibration of an object are called sound waves (Halliday \& Resnick, 1998). Various science/physics textbooks contain topics related to sound as may be divided into four different titles: formation, structure, propagation, and perception of sound (e.g., Halliday \& Resnick, 1998; Serway \& Beichner, 2002). Also, it can be seen that there are textbooks, describing the subject of sound based on a context such as the physics of music (e.g., Parker, 2015). The sound subject is included directly or indirectly in different grade levels in science/physics curriculum of many countries (e.g., MoNE, 2018a; 2018b; NGSS, 2017). It is even seen in international exams such as PISA (OECD, 2019) and TIMSS (Centurino \& Jones, 2017). These show the importance given to the teaching of the sound subject.

\footnotetext{
*Assistant Professor, Department of Elementary Education, Faculty of Education, Giresun University, Turkey.

${ }^{+}$Assistant Professor, Department of Science Education, Faculty of Education, Giresun University, Turkey.
} 
On the other hand, there are some difficulties that may be experienced in teaching the sound concept. The slow development of scientific knowledge about sound compared to other concepts may be an indicator of these difficulties. Compiling different studies, Ladachart and Nashon (2010) clarified this development process. They stated that the studies on the formation, structure, and propagation of sound started with Pythagoras in the $6^{\text {th }}$ century BC and today's definition has been reached after the explanation of the concepts of pressure and energy in the $18^{\text {th }}$ century AD. For example, it was seen that sound is perceived as a wave carrying matter. If students have this perception, it can be an obstacle to teaching the subject. Similar knowledge deficiencies/misconceptions have been detected in different student groups and teacher candidates in various articles (Beaty, 2000; Bektaş, 2015; Eshach, Lin, \& Tsai, 2016; Eshach \& Schwartz, 2006; Hrepic, 2002; Küçüközer, 2009; Mazens \& Lautrey, 2003; Maurines, 1993; Öztürk \& Atalay, 2012). Also, it is seen that learners have difficulties understanding the propagation, nature, and characteristics of the sound (Ayvac1 \& Bakırc1, 2018; Caleon \& Subramaniam, 2010; Eshach \& Schwartz, 2006; Eshach, Lin, \& Tsai, 2016; Hrepic, 2002; Hrepic, Zollman, \& Rebello, 2010; Küçüközer, 2009; Linder \& Erickson, 1989; Menchen \& Thompson, 2005; Öztürk \& Atalay, 2012). For this reason, it is useful to carry out various research to remove the obstacles in the teaching of the sound subject.

To create a solid foundation in the teaching of the sound concept, it is important to reveal the current status of previous studies. However, it was not found any study that compiles existing studies on teaching the subject of sound. Postgraduate theses that can serve as the basis for future research can be the starting point for such a review. However, the theses are mostly written in the language of the countries in which they were made and archived in each country's thesis archiving system. For this reason, it limits its contribution to the literature as its readability may remain low worldwide. It is useful to analyze the theses systematically to contribute to the literature. Considering the difficulties described above, making such an analysis on a country basis to ensure its reliability increases its contribution to the literature.

Although sound subjects are included in primary, middle, high school, and also teacher education curriculums of Turkey, academic studies related to teaching the subjects started in the recent past (in the 2000s). However, studies on the teaching of the sound subject in international literature go back to the 1980s (e.g., Linder, 1987). There has not yet, been a systematic study conducted in Turkey, that reviews the postgraduate theses on teaching the sound concept in science and physics education. The aim of this study is that theses on sound, which are written at the postgraduate level of science/physics education in Turkey, are to review. Their conclusions and suggestions of the theses were analyzed to guide future studies. Thus, a systematic summary of the literature in Turkey will be presented for science/physics teachers, researchers, and program developers. It is worth noting that it is not intended to criticize the theses within the scope of the study in terms of method or content. The aim is only to reveal the existing situation.

Planning research and relating it to existing knowledge is the building block of all research activities (Synder, 2019). This research as a review may be helpful 
for researchers, who plan to research in this area, to refresh their information base and interpret their findings (Wee \& Banister, 2016). When the theses were examined within the scope of the study, it was seen that science/physics teaching dealt with the cognitive, affective, and skill dimensions separately or together. The scope of this study is limited to theses dealing with the cognitive dimension. Therefore, although the affective dimension or skill dimension was also the subject of the thesis, only the cognitive dimension was analyzed. The cognitive dimension here is to know the related concepts in harmony with the scientific paradigm. When all these are taken into consideration, two different research questions arise. During the data analysis process of the study, it was revealed that the first question had sub-questions. The questions and sub-questions of the study are as follows:

RQ1: What are the cognitive conclusions reached in the theses about teaching the sound concept in science/physics?

RQ1-1: What are the cognitive effects of the methods/techniques/tools used in teaching the sound concept in the theses?

RQ1-2: What are the conceptual difficulties identified in the theses regarding the sound concept?

RQ2: What is suggested in the cognitive dimension to improve teaching in the theses about teaching the sound concept in science/physics?

\section{Methodology}

This study, which examined the theses in Turkey regarding the teaching of the sound concept is a semi-systematic review. One of the potential contributions of semi-systematic reviews to the research field is to map and synthesize the state of knowledge of primary research on a specific topic (Synder, 2019). Semi-systematic reviews may or may not use a systematic search strategy (Synder, 2019). In this study, it is preferred to use the systematic review process. Because the basic difference of systematic reviews from other review types is that the method is defined in detail in the systematic reviews (Gough, Thomas, \& Oliver, 2012). The first two stages of the systematic review process are developing research questions and designing a conceptual framework (Newman \& Gough, 2020). These stages are explained in the introduction part of this manuscript. The following stages are as follows:

\section{The Selection Criteria}

Research questions are based on postgraduate theses, which in Turkey need to complete a degree of master or doctoral. Graduate education in Turkey is carried out in two stages. The first stage is a master's degree and is carried out in four semesters. To complete it, a thesis in which a complete scientific research process has been carried out must be prepared and defended in front of a jury. The doctorate program, which is a similar graduation requirement, is carried out in eight semesters; and also, students, who successfully pass the qualifying exam at 
the end of four semesters, prepare research dissertation. In this study, the expression of 'thesis' is used for both types of graduation research. In the theses of master's or doctoral programs in the field of science/physics education, students are generally expected to identify a problem in the teaching/learning process and search for a solution to this problem. While some theses produce products to identify the problem, they often reveal the effect of an application. The theses are often based on primary, secondary, or high school curricula, as they often focus on existing problems.

It is essential to reach the theses made in Turkey. For this reason, the documents examined in the study were selected from the theses in the National Thesis Center of Turkey. The theses are archived in this center since 1986. The selection criteria are as follows:

i. Taking the concept of sound as a subject in science/physics

ii. Adopting the cognitive dimension of sound teaching

iii. Being in the field of education and teaching

iv. Being online open access

It has been decided that it can be stretched to be in the education and teaching field among these criteria. Even if it is not in this field, if a thesis is noticed on a subject suitable for the review, it has been decided to add it.

\section{The Search Strategy}

Theses, archived in The National Thesis Center of Turkey in the field of education and teaching, are examined to reaching the documents at last on August 20, 2020. Each of the two researchers prepared a keyword list taking into account the related literature on sound concept and then merged the two lists. The keywords were 'sound wave', 'longitudinal wave', 'sound and wave', 'physics of sound', 'sound and physics', 'sound physics', 'sound and science', 'music and wave', 'music and physics', 'music physics', 'music of physics', 'music and science', 'sound', 'sound subject', and 'sound unit' in Turkish. Also, the references (citation checking) of the theses reached in this way were examined.

\section{The Theses Selection and the Quality of Studies}

The titles and abstracts of all the theses were read by one of the researchers to determine whether the theses reached through keyword scanning are related to the research questions or not. No selection was made depending on the quality of the study, both quantitative, qualitative, and mixed-method theses were accepted in the study area. For these reasons, it should be accepted that the study is semisystematic. Five doctoral and 28 master's theses were the documents of this study (Table 1). 
Table 1. The Aims, Target Groups, and Methods of the Theses

\begin{tabular}{|c|c|c|c|c|}
\hline Theses' & Theme & Code & Master & Doctoral \\
\hline \multirow{8}{*}{ Aim } & \multirow{5}{*}{$\begin{array}{l}\text { Determining } \\
\text { the case }\end{array}$} & Knowledge & 5 & \\
\hline & & Misconception/concept error & 8 & \\
\hline & & Associating the concepts with different disciplines & 1 & \\
\hline & & Mental model & 1 & \\
\hline & & The development of textbooks & 1 & \\
\hline & \multirow{3}{*}{$\begin{array}{c}\text { Determining } \\
\text { the effect of } \\
\text { teaching }\end{array}$} & Success/access/permanence & 13 & 5 \\
\hline & & Conceptual understanding/change & 6 & 1 \\
\hline & & Other variables & 15 & 4 \\
\hline \multirow{9}{*}{$\begin{array}{l}\text { Target } \\
\text { group }\end{array}$} & \multirow{3}{*}{ Student } & Primary school & 6 & \\
\hline & & Middle school & 18 & 4 \\
\hline & & High school & 1 & \\
\hline & \multirow{4}{*}{$\begin{array}{c}\text { Teacher } \\
\text { candidate }\end{array}$} & Primary education & 1 & \\
\hline & & Science education & 2 & \\
\hline & & Physics education & 1 & 1 \\
\hline & & Music education & 1 & 1 \\
\hline & Textbook & Science & 1 & \\
\hline & Teacher & Science & 1 & \\
\hline \multirow{12}{*}{$\begin{array}{l}\text { Research } \\
\text { method }\end{array}$} & \multirow{3}{*}{ Method } & Quantitative & 9 & \\
\hline & & Qualitative & 6 & \\
\hline & & Mixed & 12 & 5 \\
\hline & \multirow{3}{*}{ Sampling } & Simple random/cluster & 6 & 2 \\
\hline & & Purposive & 9 & 1 \\
\hline & & Appropriate & 13 & 2 \\
\hline & \multirow{4}{*}{ Data } & Cognitive & 27 & 5 \\
\hline & & Affective & 14 & 4 \\
\hline & & $\begin{array}{l}\text { Skill } \\
\end{array}$ & 2 & 3 \\
\hline & & Habitat-niche/corporate recognition & 1 & \\
\hline & \multirow{2}{*}{ Analysis } & Quantitative & 22 & 5 \\
\hline & & Qualitative & 18 & 5 \\
\hline
\end{tabular}

The theses are mostly aimed to determine the effect of teaching. Various teaching methods/models/tools (as multiple intelligence theory, 5E learning model, cooperative learning, conventional and virtual laboratory applications, parent training materials, computer-assisted education, problem-based learning, STEM, interdisciplinary teaching approach, learning cycle approach, context-based learning, technology-supported inquiry-based learning, drama, game-based learning, common knowledge structuring model, straight narration, teaching by presentation, conventional teaching) are tried. Fifteen of these are aimed to compare the effect of different teachings on cognition (success, access, permanence, eliminating misconceptions), affection (attitude and motivation), or skill (success, access, permanence, eliminating misconceptions) dimension. Therewithal, when determining the situation, the focus is on the level of knowledge or misconceptions/concept errors. Everything aside, it is remarkable that theses on the sound subject especially in primary and middle school grade not only examine the sound subject, but also light subject.

The theses are mostly carried out with $6^{\text {th }}$ and $8^{\text {th }}$ grade students in the middle school. Only one thesis worked with four different target groups, secondary and high school students with science and physics teacher candidates. All of the other 
researchers worked with single grade student groups. But one thesis worked with two different teacher candidates (music and physics) groups. Unlike other theses, only one thesis examined the subject of sound in primary, secondary, and high school textbooks rather than working with students or teachers.

The mixed-method is used the most in the theses and analyzes are carried out in parallel with their methods. Hypothesis testing tests and descriptive statistics are used for quantitative data analysis. Content analysis, descriptive analysis, and document analysis are used for qualitative data analysis. The maximum variation, paired group, and criterion sampling were carried out for purposeful sampling. The data collection tools of the theses appear to be oriented towards cognitive, affective, or skill measurement/determination and document analysis in line with their aims.

\section{Coding Studies (Theses)}

The theses examined are firstly listed in alphabetical order and coded with numbers. While presenting the findings, the relevant thesis number is specified. The review was done by content analysis. For this, the stages of elimination and coding, placing them in themes, ensuring reliability and validity were followed respectively. The conclusions and suggestions of the theses were reviewed and coded inductively by one of the researchers. Then the second researcher made the same analysis. For finding the consensus about the themes of the analyze two researchers met at regular intervals and firstly combined the two analyzes, then interpreted the data.

The last two stages of the systematic review are synthesis the conclusions of the theses and reporting the findings. Synthesis of the data of this study has given in the results and conclusion of this study.

\section{Results}

The results of the study are presented under two parts as conclusions and suggestions of the reviewed theses according to the research questions.

\section{The Results related to the Cognitive Conclusions Reached in the Theses (RQ1)}

The results related to the cognitive conclusions reached in the theses presented according to sub-questions.

The Results related to the Cognitive Effects of the Methods/Techniques/ Tools used in Teaching the Sound Concept in the Theses (RQ1-1). It has been observed that the conclusions can be examined in two themes as the 'existing situation' and the 'effects of teaching' (Table 2). 
Table 2. Conclusions of the Theses

\begin{tabular}{|c|c|c|c|}
\hline Theme & Code & Expression & $\mathbf{n}$ \\
\hline \multirow{11}{*}{ 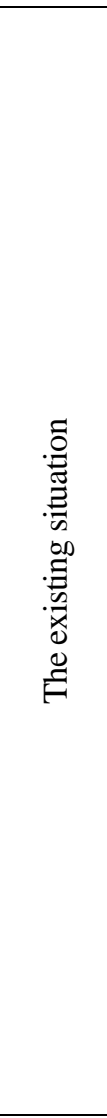 } & \multirow{4}{*}{ 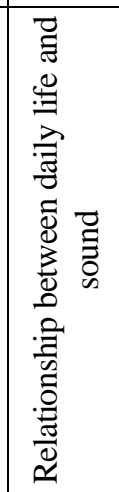 } & $\begin{array}{c}6^{\text {th }} \text { graders have difficulty explaining the events and technologies related } \\
\text { to sound. }\end{array}$ & 2 \\
\hline & & $\begin{array}{l}8^{\text {th }} \text { graders have structured most of their mental models related to sound } \\
\text { with an analogy from daily life, were influenced by the simulations used } \\
\text { in the lessons, and developed original mental models that overlap school } \\
\text { knowledge. }\end{array}$ & 1 \\
\hline & & $\begin{array}{c}\text { Middle and high school students; science, physics, music, and primary } \\
\text { school teacher candidates cannot adapt the sound concepts they learned to } \\
\text { different disciplines/new situations/daily life. }\end{array}$ & 3 \\
\hline & & $\begin{array}{l}\text { While the subjects in the textbooks are associated with daily life in every } \\
\text { period, it has increased since } 2005 \text { as sound associated with the history of } \\
\text { the economy, savings, technology, and science. }\end{array}$ & 1 \\
\hline & \multirow{5}{*}{ 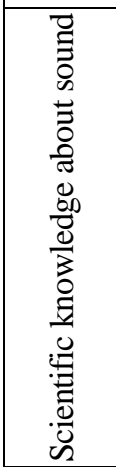 } & Students have difficulty knowing what is scientific about sound & 5 \\
\hline & & $\begin{array}{c}\text { In addition to the wave model in sound, there are five different mental } \\
\text { models in } 8^{\text {th }} \text { grade. These are existence, intrinsic, hybrid, completely } \\
\text { different, and unrelated. }\end{array}$ & 1 \\
\hline & & $\begin{array}{c}\text { The mental models of } 8^{\text {th }} \text { graders students are generally compatible with } \\
\text { scientific knowledge and school knowledge is sufficient. }\end{array}$ & 1 \\
\hline & & $\begin{array}{l}\text { Middle and high school students; science, physics, music, and primary } \\
\text { school teacher candidates have concept error/misconceptions or do not } \\
\text { have sufficient knowledge. }\end{array}$ & 6 \\
\hline & & \multicolumn{2}{|l|}{$\begin{array}{l}\text { There are confused concepts and knowledge deficiencies/misconceptions/ } \\
\text { concept errors related to sound concept (Tables } 3 \text { and 4). }\end{array}$} \\
\hline & 峞 & $\begin{array}{l}\text { In the textbooks of 1926-2005, the nature and properties of sound, sound } \\
\text { propagation, and ear health are common concepts }\end{array}$ & 1 \\
\hline & 泀 & $\begin{array}{l}\text { The differences are the use of concepts/tools related to music/acoustics } \\
\text { and the use of formulas/expressions. }\end{array}$ & 1 \\
\hline \multirow{6}{*}{ 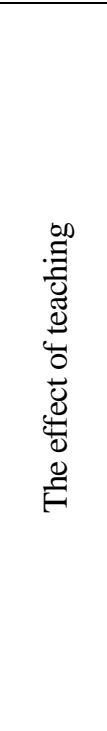 } & \multirow{3}{*}{ 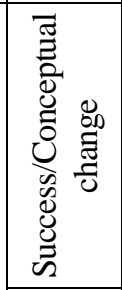 } & $\begin{array}{l}\text { The conventional education did not make any significant difference in the } \\
\text { learning of the sound subject. }\end{array}$ & 2 \\
\hline & & $\begin{array}{l}\text { With conventional education or applied teaching the success of both } \\
\text { groups is increased. }\end{array}$ & 2 \\
\hline & & $\begin{array}{l}\text { Teaching suitable for both contemporary and accordingly curriculum is } \\
\text { effective for increasing success, the applied teaching is more effective } \\
\text { than current teaching. }\end{array}$ & 15 \\
\hline & \multirow[t]{2}{*}{ 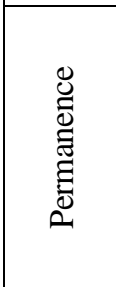 } & $\begin{array}{l}\text { Conventional, learning cycle approach, 5E learning model-based, } \\
\text { multiple intelligence theory-based, collaborative, common knowledge } \\
\text { structuring model-based, applied conceptual change texts, with the } \\
\text { analogy-supported worksheet and conceptual change text teaching is } \\
\text { effective in increasing the permanence of what is learned. }\end{array}$ & 7 \\
\hline & & $\begin{array}{l}\text { Teaching by presenting is not effective in increasing the permanence of } \\
\text { what is learned. }\end{array}$ & 1 \\
\hline & 䏤 & $\begin{array}{l}\text { All of the faculty members working in the Department of Music } \\
\text { Education and most of the faculty members working in the Department of } \\
\text { Physics Education want to teach the subject of sound knowledge and } \\
\text { acoustics as a course. }\end{array}$ & 1 \\
\hline
\end{tabular}

In Table 2, when the conclusions related to the effect of teaching are analyzed, it is seen that success and conceptual change are generally realized and the applied teaching is effective in increasing the permanence. A thesis suggested that a new course should be added to the curriculum as sound knowledge and acoustics. It is seen that students and also teachers/teacher candidates have 
difficulty adapting the sound concepts to different disciplines, new situations, and daily life.

The Results related to the Conceptual Difficulties Identified in the Theses (RQ1-2). By examining the conclusions of the learner's situations of knowing what is scientific about sound to determine the existing situation, the confused concepts (Table 3) and knowledge deficiencies/misconceptions/concept errors (Table 4) were revealed.

Table 3. Confused Concepts about Sound in The Theses

\begin{tabular}{|c|c|c|}
\hline Confused concepts & Expression & $\mathbf{n}$ \\
\hline \multirow{2}{*}{$\begin{array}{l}\text { Frequency/Highness- } \\
\text { Intensity/Amplitude }\end{array}$} & $\begin{array}{l}\text { The frequency of the sound is confused with its intensity: The } \\
\text { frequency of the sound is confused with its amplitude. Decreasing the } \\
\text { radio voice is related to both frequency and amplitude. Since bats do } \\
\text { not see with their eyes, they benefit from the intensity of the sound. }\end{array}$ & 4 \\
\hline & $\begin{array}{l}\text { The highness of the sound is confused with its intensity: When the } \\
\text { sound source is turned down, the sound starts to get thinner/the } \\
\text { frequency-highness changes. Whether the sound is thin or thick/high } \\
\text { is called the intensity of the sound. }\end{array}$ & 6 \\
\hline Frequency-Timbre & $\begin{array}{l}\text { The frequency of the sound is confused with its timbre: The timbre } \\
\text { formed by the bells hitting each other allows the bats to find their way. }\end{array}$ & 3 \\
\hline Frequency-Resonance & The thinness/thickness of the sound results from the resonance. & 1 \\
\hline Frequency-Highness & The frequency of the sound is confused with its highness. & 1 \\
\hline $\begin{array}{l}\text { Highness-Intensity- } \\
\text { Timbre }\end{array}$ & The highness, intensity, and timbre concepts are confused. & 1 \\
\hline Highness-Echo & Echo and highness are confused. & 1 \\
\hline Intensity-Timbre & $\begin{array}{l}\text { The intensity of the sound is confused with its timbre: The intensity of } \\
\text { the sounds of the musical instruments allows them to be distinguished. }\end{array}$ & 2 \\
\hline Intensity-Speed & The intensity of the sound is confused with its speed. & 1 \\
\hline Formation-Propagation & The formation of sound is confused with its propagation. & 1 \\
\hline Reflection-Absorption & The absorption and the reflection of the sound are confused. & 2 \\
\hline Reflection/Echo & The reflection and the echo of the sound are used synonymously. & 1 \\
\hline $\begin{array}{l}\text { Insulation-Reflection- } \\
\text { Echo }\end{array}$ & Sound insulation, reflection, and echo are confused. & 1 \\
\hline Energy-Intensity & $\begin{array}{l}\text { The feature that the sound is energy is confused with its } \\
\text { intensity/force. }\end{array}$ & 1 \\
\hline Echo-Propagation & Echo is known as propagation. & 2 \\
\hline
\end{tabular}

In Table 3, there are 14 different but related confusion. That the concepts of frequency, intensity, timbre, resonance, highness, and echo; the formation and propagation of the sound; the reflection and absorption of the sound are confused with each other. The confusion of the concepts of frequency/highness and intensity/amplitude appears in a significantly higher number of theses than others. It is followed by the confusion of frequency-timbre, intensity-timbre, and reflection-absorption concepts. 
Table 4. Knowledge Deficiencies/Misconceptions/Concept Errors about Sound in the Theses

\begin{tabular}{|c|c|c|c|}
\hline Theme & Code & Expression & n \\
\hline \multirow{25}{*}{ 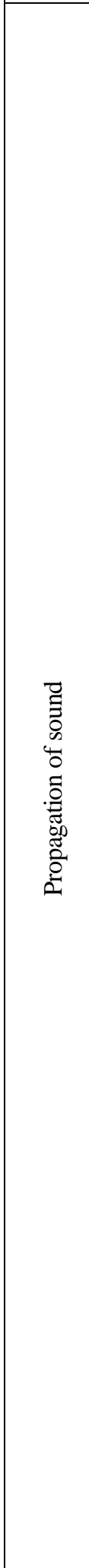 } & \multirow[t]{2}{*}{$\begin{array}{l}\text { Requirement of } \\
\text { material } \\
\text { medium }\end{array}$} & $\begin{array}{c}\text { There is no need for a material medium/there should be no substance } \\
\text { in the medium: The sound propagates in space/airless medium; travels } \\
\text { fastest in space/airless medium since there is no obstacle. We need to } \\
\text { speak loudly to propagate the sound in space. }\end{array}$ & 8 \\
\hline & & $\begin{array}{l}\text { Since there are two glasses in the double glazing, no sound is heard. } \\
\text { There is air between the double glass, so no sound can enter and exit. }\end{array}$ & 1 \\
\hline & $\begin{array}{c}\text { Sound as } \\
\text { energy transfer }\end{array}$ & $\begin{array}{c}\begin{array}{c}\text { Sound can carry matter: It can move air particles/dust particles/candle } \\
\text { flame. The dust particles in front of the speaker moves away from the } \\
\text { sound source. }\end{array} \\
\end{array}$ & 2 \\
\hline & \multirow{2}{*}{$\begin{array}{l}\text { Propagation by } \\
\text { vibrating the } \\
\text { medium }\end{array}$} & Sound does not vibrate. & 1 \\
\hline & & Sound is transmitted by reflection/echo. & 1 \\
\hline & \multirow{3}{*}{$\begin{array}{l}\text { Propagation } \\
\text { direction }\end{array}$} & Sound moves away from the source. & 1 \\
\hline & & Sound is propagated linearly. & 2 \\
\hline & & Sound cannot propagate in all directions. & 1 \\
\hline & \multirow{7}{*}{$\begin{array}{l}\text { Absorption of } \\
\text { sound/ } \\
\text { insulation }\end{array}$} & Sound stops by hitting an obstacle. & 1 \\
\hline & & As sound propagates in waves, it wears and disappears. & 1 \\
\hline & & $\begin{array}{c}\text { Sound does not travel in solids and water: However, it passes a little } \\
\text { through the liquid and much more than gas. }\end{array}$ & 3 \\
\hline & & $\begin{array}{c}\text { Sound is absorbed more on flat surfaces: Hard and smooth surfaces } \\
\text { such as iron and concrete can be used in theatre/cinema halls for sound } \\
\text { insulation. }\end{array}$ & 2 \\
\hline & & $\begin{array}{l}\text { Absorption of sound is that it does not find a material medium for } \\
\text { propagation. }\end{array}$ & 1 \\
\hline & & $\begin{array}{l}\text { Wool, felt, fabric, carpet, fibbers, double glazing, and rubber are not } \\
\text { but metals are insulation materials. }\end{array}$ & 2 \\
\hline & & In absorption, energy evanesces instead of transforming. & 1 \\
\hline & \multirow{3}{*}{$\begin{array}{l}\text { Reflection of } \\
\text { sound/echo }\end{array}$} & Soft/hard and rough/smooth surfaces reflect more sound. & 2 \\
\hline & & Reflection of sound does not occur on a curved surface. & 1 \\
\hline & & Sound can propagate in all mediums but cannot reflect. & 1 \\
\hline & \multirow{7}{*}{ Speed of sound } & $\begin{array}{l}\text { Sound is faster when space/distance between the particles/molecules } \\
\text { of the medium in which the sound is propagated is greater. }\end{array}$ & 2 \\
\hline & & $\begin{array}{l}\text { The large size of the particles/molecules of the medium in which the } \\
\text { sound propagates does not affect the speed of the sound/makes the } \\
\text { sound faster. }\end{array}$ & 1 \\
\hline & & $\begin{array}{l}\text { Sound propagates/is transmitted faster in gases/air than in liquids and } \\
\text { solids: The sound does not find too many obstacles in the gases/air to } \\
\text { slow. Intervening obstacles negatively affects the transmission of } \\
\text { sound. }\end{array}$ & 9 \\
\hline & & Sound propagates least in the liquid mediums. & 1 \\
\hline & & $\begin{array}{l}\text { The speed of sound is not affected by the physical state of the } \\
\text { medium: Solid substances do not affect/slow down the speed of } \\
\text { sound. }\end{array}$ & 2 \\
\hline & & $\begin{array}{c}\text { When the density of the medium is high, sound propagates fast: Sound } \\
\text { is faster in solids due to echo. Since the density of solids is less, sound } \\
\text { propagates faster. Since there is no air in the atmosphere, sound } \\
\text { propagates faster in solid. }\end{array}$ & 2 \\
\hline & & $\begin{array}{c}\text { The speed of sound propagation depends on its frequency and its } \\
\text { intensity, loudness, and timbre. }\end{array}$ & 2 \\
\hline
\end{tabular}




\begin{tabular}{|c|c|c|c|}
\hline & & $\begin{array}{c}\text { The energy of the source, being high or deep pitched, and the length of } \\
\text { the object which the sound propagates do not affect/change the speed } \\
\text { of the sound and also change the frequency and amplitude. }\end{array}$ & 2 \\
\hline & & $\begin{array}{l}\text { The increase of the medium temperature does not affect/decrease the } \\
\text { speed of the sound. }\end{array}$ & 2 \\
\hline & & Sound waves are reflected more slowly in a warmer medium. & 1 \\
\hline & & $\begin{array}{l}\begin{array}{c}\text { Sound and light propagate at the same speed: You can see and hear a } \\
\text { distant event at the same time. }\end{array} \\
\end{array}$ & 2 \\
\hline \multirow{9}{*}{ 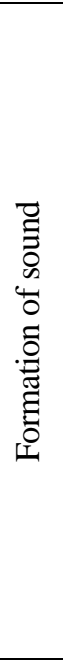 } & \begin{tabular}{|c|} 
Sound as \\
energy transfer
\end{tabular} & \begin{tabular}{|c|} 
Sound is/isn't a form of energy. \\
Sound is an entity. \\
\end{tabular} & 3 \\
\hline & \multirow{3}{*}{$\begin{array}{c}\text { Requirement of } \\
\text { a material } \\
\text { medium }\end{array}$} & $\begin{array}{l}\text { Sound may be formed in space/airless medium: It is formed by the } \\
\text { fact that the intermolecular space is quite large and there is no } \\
\text { obstacle. }\end{array}$ & 2 \\
\hline & & There is no need for a material medium for the formation of sound. & 1 \\
\hline & & No sound vibrations are formed in the cold medium. & 1 \\
\hline & \multirow{2}{*}{\begin{tabular}{|c|}
$\begin{array}{c}\text { Requirement of } \\
\text { vibration }\end{array}$ \\
\end{tabular}} & Sound is formed by the collision of vocal cords. & 1 \\
\hline & & Sound is formed by the reflection of molecules from a surface. & 1 \\
\hline & \multirow{2}{*}{$\begin{array}{l}\text { Vibration } \\
\text { frequency }\end{array}$} & $\begin{array}{l}\text { When the water is too high in a closed container, the sound will be } \\
\text { deeper as the water also sounds. }\end{array}$ & 1 \\
\hline & & $\begin{array}{l}\text { The frequency of the sound may change with the intensity of the } \\
\text { sound/force applied to the object and the temperature. }\end{array}$ & 1 \\
\hline & $\begin{array}{l}\text { Formation } \\
\text { through } \\
\text { resonance }\end{array}$ & With the highness of the sound, the windows vibrate and break. & 1 \\
\hline \multirow{7}{*}{ 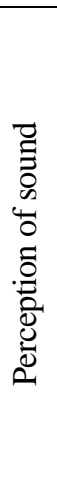 } & \multirow{4}{*}{$\begin{array}{c}\text { The effect of } \\
\text { the medium on } \\
\text { hearing }\end{array}$} & $\begin{array}{l}\text { Sounds formed in different mediums cannot be heard or may not be } \\
\text { heard. }\end{array}$ & 2 \\
\hline & & $\begin{array}{c}\text { Sound is heard by hitting some substances in the air: Sound is heard } \\
\text { better in the air. Because it travels in larger areas and reflects more by } \\
\text { hitting. With the reflection of the sound waves, both of our ears hear } \\
\text { the sound. }\end{array}$ & 2 \\
\hline & & It is heard more in substances with high sound absorption. & 1 \\
\hline & & Sound is heard in the presence of oxygen gas. & 1 \\
\hline & \multirow{2}{*}{$\begin{array}{l}\text { Hearing } \\
\text { threshold }\end{array}$} & Dogs hear better because their auricles are bigger. & 1 \\
\hline & & $\begin{array}{l}\text { People cannot hear some of the sounds that dogs hear because their } \\
\text { frequency is high. }\end{array}$ & 1 \\
\hline & Hearing & The reason we hear the sound is absorption, echo, or reflection. & 1 \\
\hline
\end{tabular}

First of all, it should be noted that whether the statements in Table 4 are true or false, are not discussed in detail because this is not the purpose of the study. In Table 4, it is seen that there are more knowledge deficiencies/misconceptions/ concept errors about the speed of sound in "propagations of sound" than other subjects. "Sound as energy transfer", the "requirement of a material medium", and "vibration emerges" in both the formation and propagation of sound themes.

\section{The Results related to Suggestions in the Cognitive Dimension to Improve Teaching in the Theses (RQ2)}

Findings about the suggestions of the theses are presented in Table 5. 
Table 5. Suggestions of the Theses

\begin{tabular}{|c|c|c|}
\hline Theme & Expressions & $\mathbf{n}$ \\
\hline \multirow{3}{*}{$\begin{array}{l}\text { To different } \\
\text { researchers }\end{array}$} & $\begin{array}{l}\text { The study can be repeated with different sample/study groups, teaching } \\
\text { methods/activities, and data collection tools for different variables. }\end{array}$ & 19 \\
\hline & $\begin{array}{c}\text { The source of misconceptions or mental models about sound can be } \\
\text { investigated. }\end{array}$ & 2 \\
\hline & $\begin{array}{l}\text { The consistency of the concepts used in the textbooks with scientific } \\
\text { knowledge can be revealed. }\end{array}$ & 1 \\
\hline $\begin{array}{l}\text { To different } \\
\text { researchers/ } \\
\text { teachers }\end{array}$ & $\begin{array}{l}\text { Existing situations of students/prospective teachers/teachers on the subject of } \\
\text { sound can be determined. }\end{array}$ & 8 \\
\hline \multirow{5}{*}{ To teachers } & $\begin{array}{l}\text { Environments that can eliminate the problems experienced in teaching } \\
\text { concepts about sound can be organized/studies can be done to eliminate } \\
\text { misconceptions. }\end{array}$ & 9 \\
\hline & $\begin{array}{l}\text { The applied teaching method/model/technique/material can be applied to } \\
\text { different education levels or concepts. }\end{array}$ & 12 \\
\hline & $\begin{array}{l}\text { An interdisciplinary approach, based on the relationship between music and } \\
\text { science/physics, can be utilized at every education level to increase success. }\end{array}$ & 4 \\
\hline & The daily life relationship of teaching should not be ignored. & 7 \\
\hline & Out-of-class learning environments can be created. & 2 \\
\hline \multirow{3}{*}{$\begin{array}{l}\text { To curriculum } \\
\text { makers }\end{array}$} & $\begin{array}{l}\text { The existing curriculums for the teaching of the sound subject should be } \\
\text { updated or new lessons should be opened on the subject. }\end{array}$ & 5 \\
\hline & $\begin{array}{l}\text { While updating the curriculum, original contents can be prepared by going } \\
\text { beyond past curriculums. }\end{array}$ & 1 \\
\hline & $\begin{array}{c}\text { The duration of the courses in which the subject of sound is taught should be } \\
\text { regulated in teacher education programs. }\end{array}$ & 1 \\
\hline $\begin{array}{l}\text { To teaching } \\
\text { tool/material } \\
\text { developers }\end{array}$ & $\begin{array}{l}\text { New materials or technology-aided environments should be designed to } \\
\text { eliminate the need for material for teachers. }\end{array}$ & 3 \\
\hline $\begin{array}{l}\text { To textbook } \\
\text { writers }\end{array}$ & $\begin{array}{l}\text { The consistency of the visual elements in the textbooks with scientific } \\
\text { knowledge should be reviewed and necessary arrangements should be made. }\end{array}$ & 6 \\
\hline $\begin{array}{l}\text { To teacher } \\
\text { educators }\end{array}$ & $\begin{array}{c}\text { Pedagogical content knowledge of the pre-service and in-service teachers } \\
\text { should be increased. }\end{array}$ & 6 \\
\hline
\end{tabular}

In Table 5, it is seen that suggestions are presented mostly to different researchers and teachers. The most prominent of these suggestions is to repeat similar studies, to use similar teaching methods by teachers, and to identify and eliminate misconceptions. Besides, it is also frequently suggested that the pedagogical content knowledge of in-service or pre-service teachers should be increase.

The most common suggestion offered to teachers who are practitioners of teaching is to focus on teaching concepts related to sound. Besides, it is emphasized that it is beneficial to focus on the interdisciplinary approach in the teaching of sound, together with the importance of the daily life relationship. Beyond all these, it has been suggested that it is beneficial to update the existing curricula for teaching the sound topic for curriculum makers.

\section{Discussion}

When the conclusions of the theses on science/physics education in Turkey to guide the teaching of the sound concept were reviewed, it was seen that they can 
be grouped under two headings as the results related to the existing situation and the effect of teaching. It was determined that the knowledge levels of students/ teacher candidates related existing situation is generally insufficient, they have misconceptions/concept errors, and they cannot associate their knowledge with daily life. However, the conclusions differ in two different theses conducted at the secondary level, although similar data collection tools were used: It is stated in one of them that students' mental models are related to daily life and their scientific knowledge is sufficient. It is stated in other that students cannot associate their knowledge with daily life, their knowledge level is insufficient, and they have misconceptions/concept errors. Although this may be due to the characteristics of the studied student group, it is obvious that it is useful to examine the situation in detail.

Possible misconceptions that arise in this study are related to 'propagation', 'formation', and 'perception' of sound. Although there are similar misconceptions in studies examining the misconceptions about sound, there are differences in the classifications. For example, in different studies, pre-service teachers' misconceptions about sound are classified as "the propagation and nature", "the characteristics", and "its propagation and the characteristics" of the sound (Küçüközer, 2009). Also, Öztürk and Atalay (2012) are classified as 'propagation', 'nature', and 'characteristics' of sound. It is seen that the theme of the formation of sound in this study corresponds to the nature and/or characteristics of sound themes in other studies. However, the misconceptions related to the "perception of sound" encountered in this study were not emphasized in other studies.

It was determined that students/teacher candidates had problems with the 'propagation of sound' in the theses that were concluded that there were knowledge deficiencies/misconceptions/concept errors. Various misconceptions about the propagation of sound have also been found in different studies. These misconceptions are generally predicted to arise from the perception of sound not as an energy transfer but as a matter transfer (Atasoy, Tekbıyık, \& Gülay, 2013; Hrepic, 2002; Hrepic, Zollman, \& Rebello, 2010). In a study that deals with the subject of waves as a whole, the role of air in sound propagation was described as a problematic conceptual area (Caleon \& Subramaniam, 2010). In the list of possible misconceptions that emerged in this study, it was seen that there were various explanations in the codes the "requirement of a material medium", "sound as energy transfer", and "propagation by vibrating the medium". On the other hand, it is noteworthy that the same misconceptions are also presented in the "formation of sound" theme. Related to the formation of sound is encountered that students/teacher/candidates perceive the sound as a matter transporter, not an energy transporter. Therefore, there is no need for a material medium or vibration to occur of sound and misinterpretation of the frequency of the sound source. It can be said that the misconceptions related to sound formation and propagation are related to each other and that they arise because the sound is perceived as a substance. Eshach, Lin, and Tsai (2016) stated that the answers to the questions of some of the participants in their study are associate with materialistic properties. However, Küçüközer (2009) also found that the conceptual understanding of the 
propagation and nature of sound was far from being scientific in his study examining the misconceptions about sound.

The most common misconception in the theses is related to the requirement of material medium for propagation. Ayvacı and Bakırcı (2018) also found that these misconceptions, which we encounter in many studies, have existed in students since primary school. They tried to make sense of this situation for two different reasons. First, they attributed the related outcome to the secondary school level due to the spiral education model approach structure in the curriculum. According to the current curriculum, "it predicts the environments in which sound can spread and tests its predictions" ( $5^{\text {th }}$ grade), and "it is stated why the sound does not spread in space" $\left(6^{\text {th }}\right.$ grade) achievements are at the secondary school level (MoNE, 2018a). The second is that the sounds of explosions can be heard in movies and cartoons about space, or that a person wearing an astronaut suit can hear what other people are saying.

It is also seen that there are problems with the "perception of sound". Related to the "propagation of sound" it is encountered also that students/teachers/ candidates interpret the effect of medium on the speed of sound as wrong because the sound does not need a material medium and vibration of medium to propagation. There are misinterpretations about the effect of the medium on hearing as well as the hearing threshold related to the perception of sound. In another perspective, knowledge deficiencies/misconceptions about sound perception are stated less than others. This may be that researchers do not need to research due to the lack of detail in the science/physics curriculum. This situation appears as learning difficulties related to standing waves in the literature (Zeng et al., 2014) and the subject of standing waves is more related to obtaining sound from instruments. Due to take place in the science/physics curriculum in Turkey, the issues of the theses not faced with such a misconception.

Also, it is seen that students/teacher candidates confuse some concepts related to sound. Concepts of frequency and intensity are confused mostly. Moreover, it is stated in the literature that teacher candidates cannot associate the intensity and lowness/highness of voice with neither the amplitude nor the frequency characteristics of the sound wave (Küçüközer, 2009). The reason why these two concepts are confused in particular, may because they are related to both the formation, propagation, and perception of sound. Another confused concept is timbre. It has been determined that timbre is confused with frequency in some theses and with intensity in some other theses. In the literature, it is seen that the concept of timbre is not known by students at lower grade levels, but it is tried to be explained with concepts such as the intensity of the voice, the tone of the voice, the loudness of the voice, and the length of the vocal cords at the higher grade levels (Ayvac1 \& Bakırc1, 2018). Although all of these concepts are related to sound, it is seen that there are not suitable concepts to explain timbre. Although the comparison of echo and propagation concepts that appear in two theses is surprising for researchers, this confusion is also encountered in a different study in the literature (Ayvacı \& Bakırc1, 2018).

The inability of students to adapt their knowledge of sound to new situations or daily life may be due to knowledge deficiencies/misconceptions. Many 
misconceptions have been detected in different learning levels. Students and teacher candidates to be more successful in similar subjects and have similar misconceptions, can be an indication that the success of the teacher in any subject can lead to the student's success in that subject. Accordingly, as Shulman (1986) stated, studies are needed make to teachers/candidates gain the ability to be aware of students' misconceptions and to do the necessary applications to overcome these misconceptions. Considering this result, it is useful to try various teaching methods to overcome the problem. For this, it is suggested that relations should be established between topics and these relations should be express by students as using concepts. Moreover, students should be provided to relate by justifying in this process. In the theses, the results related to the effects of both conventional and contemporary approaches to the teaching of the sound subject are presented. Only two theses concluded that teaching conventional does not affect the teaching of the sound concept. In contrast, all other theses concluded that it had a positive effect, but contemporary approaches more successful. On the other hand, according to some other studies, many misconceptions on sound or physics have been stable after conventional education (Atasoy, Tekbıyık, \& Gülay, 2013; Neidorf et al., 2020). In addition to this, both music education and physics education faculty members stated that the sound subject should be included in the courses and programs to be taught interdisciplinary.

Beyond the possible misconceptions discussed above, in one of the theses examined, it was found that students' mental models about sound were compatible with the scientific paradigm. However, in this thesis, the study group is middle school students. When the related curriculum is examined, it is seen that the wave property of the sound has not been explained to the students yet. On the other hand, in a thesis that was studied with middle school students, in addition to the wave model of students, five different mental models are determined. In this case, six different models were identified in total: Wave, existence, intrinsic, hybrid (swinging, longitudinal swinging, air production, air vibration, ether), completely different, and unrelated. In earlier two studies, there are eight different mental models: Hrepic (2002) and Hrepic, Zollman, and Rebello (2010) working with undergraduate students introduced shaking, longitudinally shaking, propagating, vibrating, ether, ether, and compression models together with wave model and entity model. They described the last six of them as hybrid or blend. The entity model mentioned here is referred to as substance schema or materialistic properties of the substance in the studies of Eshach, Lin, and Tsai (2016) and Eshach and Schwartz (2006). Linder and Erickson (1989) explained this by using the word thing: “... sound as a 'thing', which was either carried by molecules through a medium or was sequently passed from one molecule to the next in collision or conduction-like process". However, Linder (1992) has also tried to explain what can be done about conceptual difficulties in this context. Their emphasis was on the subject of sound "more than a chalk-and-talk presentation of formulae, observationally based calculation and conceptual exploration". In another research Mazens and Lautrey (2003), mentioned that they found four different mental models and "did not find two distinct groups of children, those who attribute all properties of matter to sound and those who do not attribute any 
of those properties to sound": Sound cannot pass through other objects unless there are holes, sound can pass through solids if it is harder than they are, the sound is immaterial, and sound is a vibratory process. At the same time, they found in their research that "conceptual change in knowledge about sound does not happen through the sudden transfer of the concept from the ontological category of matter to the ontological category of processes, but rather through a slow and gradual process of belief revision".

In the theses, suggestions were given to different researchers, teachers, curriculum makers, textbook writers, teaching tool/material developers, and teacher educators. While different researchers were offered suggestions about the method of research more, teachers were offered suggestions for teaching the concept of sound. It is recommended to use contemporary approaches such as the interdisciplinary approach in teaching sound. In the early 2000s, it was thought that there was not enough evidence that interdisciplinary teaching was more successful than conventional teaching (Chrysostomou, 2004). However, such as Science-Technology-Society-Environment, context-based, and Science, Technology, Engineering, and Mathematics (STEM) education approaches may be a sign that education researchers (Aygün \& Tan, 2020; Dedetürk, Saylan-Kırmızıül, \& Kaya, 2021; Hacioglu \& Gulhan, 2021) accept that interdisciplinary teaching is somehow effective today. In the theses examined in this context, it was seen that the context/theme of music was chosen for the teaching of sound. It is seen that there are many books in the literature on the physics of music. On the other hand, considering that there are varieties of interdisciplinary teaching, it may be beneficial to make appropriate integrations. At this point, one should be careful listening to music in the background when studying a discipline or learning a song about a subject that is not an interdisciplinary curriculum (Chrysostomou, 2004). In fact, instead of using music to learn science, it is possible to learn both music and science at the same time.

In the theses, the 5E learning model has been tried most and it has been found effective in teaching. On the other hand, the suggestions regarding the teaching of the concepts were also emphasized. The use of the constructivist approach in the teaching of sound and the importance of concept teaching appear in different studies (Atasoy, Tekbıyık, \& Gülay, 2013; Küçüközer, 2009). It is recommended to consider the use of concepts in everyday language while planning lessons on concept teaching (Ayvac1 \& Bakırc1, 2018). In the theses examined, textbook authors and individuals who prepare curriculum and course material were offered suggestions to prepare materials and content suitable for the subject. Recommendations on material emphasize the need to make the subject concrete. In different studies, the necessity of preparing materials for this need is emphasized (Küçüközer, 2009). On the other hand, it is beneficial for teachers to be subjected to various training to use materials that can be developed for concept-focused teaching of sound (Atasoy, Tekbıyık, \& Gülay, 2013). Researchers emphasize new and technology-aided materials or environments in their theses. In the literature, it is seen that technology-supported teaching positively affects the success in teaching sound (Anggraeni, Sukarmin, \& Nurosyid, 2019; Pektaş, Çelik, Katranc1, \& Köse, 2009; Şenel-Çoruhlu, Er-Nas, \& Keleş, 2016). In addition to the expectations of 
new materials and technology-aided environments, researchers have also stated that there is an increase in visual representations in textbooks. These suggestions are based on understanding Eshach and Schwartz's (2006) determination that students prefer non-verbal representations to explain the concept of sound. Because when a student wants to envision the sound, which is actually an energy, in the mind of the student, perhaps this needs for animation may lead him to an error by pushing him to give the sound a materialistic perspective. Therefore, as in the studies examined in this research, Eshach and Schwartz's suggestion is as follows: "teachers should find ways to introduce visual representations that will lead to the scientific understanding of sound, and at the same time explain that those representations have limits and are not accurate descriptions of the behavior of sound." However, in a study about standing wave explanations in textbooks, it was revealed that students understood the subject better with the air molecule motion illustration approach. In this context, the importance of the visual elements in the textbooks with scientific knowledge should be reviewed and necessary arrangements should be made can be understood. Although some of the theses emphasized that pre-service and in-service teacher training should be carried out.

\section{Conclusions and Recommendations}

Although the studies examined within the scope of this study belong to a certain region, the previous literature shows us that the learning difficulties or misconceptions are generally independent of culture. The most important output of this study is the lists of possible misconceptions or confusion about the concept of sound. The effect of teaching was examined in many theses, it was observed that the activities performed, even if the conventional education, had positive effects on the teaching of the sound subject. On the other hand, it turns out that basic concepts such as frequency, highness, and intensity are confused by different levels of students, teachers, or teacher candidates. At the same time, it has been revealed that students, teachers, or teacher candidates at different levels may lack information about many of the basic concepts related to sound, and even misconceptions. It is beneficial to consider this situation in education. In this case, it is seen that the underlying reasons for the difficulties experienced by students, teachers, or teacher candidates are not clear. Therefore, studies should be done to investigate and clarify this issue.

It has been concluded in the theses about the sound that students/teacher candidates and even teachers have various misconceptions/concept errors or confusions and some of them cannot be eliminated even with the contemporary approaches that have been tried. Therefore, studies examining the effect of approaches can be diversified and increased. Besides, studies demonstrate in which situations the effects of the tried approaches are more effective. In these studies, it can be deduced from the conclusions of the theses that it is necessary to focus on the misconception/confusion rather than the effect of teaching on success.

The theses generally focus on middle school students. However, the planner and practitioner of the teaching are teachers. For this reason, it may be beneficial 
to study with teacher candidates, teachers, and even teacher trainers in future research about the teaching of the sound subject. At the same time, considering the importance of education before choice of profession/career, it can be suggested to expand and diversify the target group to preschool, primary and high school students.

\section{Acknowledgments}

This research is the expanded version of the paper presented at the National Physics Education Congress held in Trabzon on 27-29 September 2019.

\section{References}

Anggraeni, D. P., Sukarmin, \& Nurosyid, F. (2019). Teaching Sound Waves Using Gamelan and Smartphones. Journal of Physics: Conference Series, 1153(1), 012123.

Atasoy, Ş., Tekbiyık, A., \& Gülay, A. (2013). The Effect of Concept Cartoons on Understanding of Sound Concept of Fifth Grade Students. Journal of Turkish Science Education, 10(1), 176-196.

Aygün, M., \& Tan, M. (2020). Designing, Developing and Applicability of Orientiring and Formula 1 Contexted Course Plans for Physics Teaching. Milli Eğitim Dergisi, 49(228), 263-299.

Ayvacı, H. Ş., \& Bakırcı, H. (2018). Examining Conceptual Development of Sound in Students from Different Class Grades. Journal of Instructional Technologies \& Teacher Education, 7(1), 1-17.

Beaty, W. J. (2000). Children's Misconceptions about Science. American Institute of Physics.

Bektaş, O. (2015). Pre-service Science Teachers' Pedagogical Content Knowledge in The Physics, Chemistry, and Biology Topics. European Journal of Physics Education, 6(2), 41-53.

Caleon, I., \& Subramaniam, R. (2010). Development and Application of a Three-Tier Diagnostic Test to Assess Secondary Students' Understanding of Waves. International Journal of Science Education, 32(7), 939-961.

Centurino, V. A. S., \& Jones, L. R. (2017). TIMSS 2019 Science Framework. In I. V. S. Mullis \& M. O. Martin (eds.), TIMSS 2019 Assessment Frameworks (pp. 27-57).

Chrysostomou, S. (2004). Interdisciplinary Approaches in the New Curriculum in Greece: A Focus on Music Education. Arts Education Policy Review, 105(5), 23-30.

Dedetürk, A., Saylan-Kırmızıgül, A., \& Kaya, H. (2021). The Effect of STEM Activities on $6^{\text {th }}$ Grade Students' Conceptual Development of Sound. Journal of Baltic Science Education, 20(1), 21-37.

Eshach, H., \& Schwartz, J. L. (2006). Sound Stuff? Naive Materialism in Middle-School Students' Conceptions of Sound. International Journal of Science Education, 28(7), 733-764.

Eshach, H., Lin, T. C., \& Tsai, C. C. (2016). Taiwanese Middle School Students' Materialistic Concepts of Sound. Physical Review Physics Education Research, 12(1), 010119.

Gough, D., Thomas, J., \& Oliver, S. (2012). Clarifying Differences Between Review Designs and Methods. Systematic Reviews, 1(28), 1-9. 
Hacioglu, Y., \& Gülhan, F. (2021). The Effects of STEM Education on the Students' Critical Thinking Skills and STEM Perceptions. Journal of Education in Science, Environment and Health (JESEH), 7(2), 139-155.

Halliday, D., \& Resnick, R. (1998). Fundamentals of Physics I. Translated by C. Yalçın. Ankara: Arkadaş.

Hrepic, Z. (2002). Identifying Students' Mental Models of Sound Propagation. Unpublished Master's Thesis. Manhattan, Kansas: Kansas State University.

Hrepic, Z., Zollman, D. A., \& Rebello, N. S. (2010). Identifying Students' Mental Models of Sound Propagation: The Role of Conceptual Blending in Understanding Conceptual Change. Physical Review Special Topics-Physics Education Research, 6(2), 020114.

Küçüközer, A., (2009). Investigating Prospective Science Teachers' Misconceptions of Sound. Elementary Education Online, 8(2), 313-321.

Ladachart, L., \& Nashon, S. (2010). Alternative Frameworks in Conceptions of Sound: A Historical Evolution. International Journal of Education, 33(2), 3-24.

Linder, C. J. (1987). Tertiary Physics: A Case Study in Students' Conceptions of Sounds. In J. Novak (ed.), Proceedings of the second international seminar on misconceptions and educational strategies in science and mathematics (Volume 3). New York: Cornell University.

Linder, C. J. (1992). Understanding Sound: So What Is The Problem? Physics Education, 27(5), 258-264.

Linder, C. J., \& Erickson, G. L. (1989). A Study of Tertiary Physics Students' Conceptualizations of Sound. International Journal of Science Education, 11(5), 491501.

Maurines, L. (1993). Spontaneous Reasoning on The Propagation of Sound. In J. Novak (ed.), Proceedings of the Third International Seminar on Misconceptions and Educational Strategies in Science and Mathematics. Ithaca.

Mazens, K., \& Lautrey, J. (2003). Conceptual Change in Physics: Children's Naive Representations of Sound. Cognitive Development, 18(2), 159-176.

Menchen, K. V. M., \& Thomson, J. R. (2005). Student Understanding of Sound Propagation: Research and Curriculum Development. In AIP Conference Proceedings, 790, 81.

Ministry of National Education - MoNE (2018a). Fen Bilimleri Dersi Öğretim Programı (Science Course Curriculum). Board of Education.

Ministry of National Education - MoNE (2018b). Ortaögretim Fizik Dersi Öğretim Programı (Secondary Education Physics Course Curriculum). Board of Education.

Neidorf, T., Arora, A., Erberber, E., Tsokodayi, Y., \& Mai, T. (2020). Student Misconceptions and Errors in Physics and Mathematics: Exploring Data from TIMSS and TIMSS Advanced. Springer.

Newman, M., \& Gough, D. (2020). Systematic Reviews in Educational Research: Methodology, Perspectives and Application. In O. Zawacki-Richter, M. Kerres, S. Bedenlier, M. Bond, \& K. Buntins (eds.), Systematic Reviews in Educational Research (pp. 3-22). Springer.

Next Generation Science Standards - NGSS (2017). Topic Arrangements of The Next Generation Science Standards. NGSS.

Organisation for Economic Co-operation and Development - OECD (2019). PISA 2018 Science Framework, in PISA 2018 Assessment and Analytical Framework. OECD.

Öztürk, N., \& Atalay, N. (2012). Analyzing Pre-Service Teachers' Misconceptions about Sound. Inönü University Journal of The Faculty of Education, 13(1), 43-58.

Parker, B. (2015). Good Vibrations: The Physics of Music. Translated by C. Güray, \& M. Sözer. TÜBITTAK. 
Pektaş, H. M., Çelik, H., Katranc1, M., \& Köse, S. (2009). Effect of Computer-Based Instruction Material on Student Success in Sound and Light Unit at $5^{\text {th }}$ Grade. Kastamonu Education Journal, 17(2), 649-658.

Şenel-Çoruhlu, T., Er-Nas, S., \& Keleş, E. (2016). Evaluation of Efficacy the Web Based Instructional Material Prepared According to Brain Based Learning Approach: "Light and Sound" Unit. Amasya Education Journal, 5(1), 104-132.

Serway, R. A., \& Beichner, R. J. (2002). Physics for Scientists and Engineers I. $5^{\text {th }}$ Edition. Translated by K. Çolakoğlu. Palme.

Shulman, L. S. (1986). Those Who Understand: Knowledge Growth in Teaching. Educational Researcher, 15(2), 4-14.

Snyder, H. (2019). Literature Review as A Research Methodology: An Overview and Guidelines. Journal of Business Research, 104(Nov), 333-339.

Wee, B. V., \& Banister, D. (2016). How to Write a Literature Review Paper? Transport Reviews, 36(2), 278-288.

Zeng, L., Smith, C., Poelzer, G. H., Rodriguez, J., Corpuz, E., \& Yanev, G. (2014). Illustrations and Supporting Texts for Sound Standing Waves of Air Columns in Pipes in Introductory Physics Textbooks. Physical Review Special Topics-Physics Education Research, 10(2), 020110. 
